\title{
Global variation of body-wave attenuation in the upper mantle from teleseismic $P$ wave and $S$ wave spectra
}

\author{
Y. K. Hwang, ${ }^{1}$ J. Ritsema, ${ }^{1}$ and S. Goes ${ }^{2}$ \\ Received 18 January 2011; revised 1 March 2011; accepted 7 March 2011; published 30 March 2011.
}

[1] We constrain the spatial variation of P-wave $\left(t_{P}^{*}\right)$ and S-wave $\left(t_{S}^{*}\right)$ attenuation by inverting 190,000 teleseismic $\mathrm{P}$ - and $\mathrm{S}$-wave spectra up to $0.8 \mathrm{~Hz}$. These spectra are derived from 250 deep earthquakes recorded at 880 broadband global and regional network stations. The variance and ratios of $t_{P}^{*}$ and $t_{S}^{*}$ values are consistent with PREM's upper mantle velocity and $Q$ structures and conventional $t_{P}^{*}$ and $t_{S}^{*}$ values. High attenuation is resolved beneath stations in tectonically active regions characterized by high heat flow. Low attenuation marks stable continental regions. The maps of $t_{P}^{*}$ and $t_{S}^{*}$ correlate well with the variations of $t_{S}^{*}$ computed and inferred from (1) the most recent surfacewave $Q$ model and (2) a thermal interpretation of shear-wave velocity tomography. This indicates that maps of body- and surface-wave attenuation reflect intrinsic attenuation and variable temperature in the mantle. Citation: Hwang, Y. K., J. Ritsema, and S. Goes (2011), Global variation of body-wave attenuation in the upper mantle from teleseismic $\mathrm{P}$ wave and $\mathrm{S}$ wave spectra, Geophys. Res. Lett., 38, L06308, doi:10.1029/ 2011 GL046812.

\section{Introduction}

[2] Models of the elastic velocity structure of the mantle have advanced our knowledge of mantle dynamics [e.g., Romanowicz, 2008], but are by themselves insufficient to obtain complete descriptions of the physical state of Earth's interior. Anelasticity models can provide important complementary information. Anelasticity has a much stronger sensitivity to temperature and water content than elastic velocities, a lower sensitivity to composition and a different sensitivity to melt [e.g., Anderson, 1967; Karato and Jung, 1998; Hammond and Humphreys, 2000; Jackson et al., 2002; Faul et al., 2004; Shito et al., 2006].

[3] A number of studies have mapped the global variation of seismic wave attenuation in the upper mantle using surface waves [e.g., Romanowicz, 1995; Billien et al., 2000; Gung and Romanowicz, 2004; Selby and Woodhouse, 2002; Dalton and Ekström, 2006; Dalton et al., 2008] and body waves [e.g., Bhattacharyya et al., 1996; Reid et al., 2001; Warren and Shearer, 2002; Lawrence and Wysession, 2006]. Here we add a new estimate of attenuation in the upper mantle from teleseismic $\mathrm{P}$-wave and $\mathrm{S}$-wave spectra.

\footnotetext{
${ }^{1}$ Department of Geological Sciences, University of Michigan, Ann Arbor, Michigan, USA.

${ }^{2}$ Department of Earth Science and Engineering, Imperial College London, London, UK.

Copyright 2011 by the American Geophysical Union. 0094-8276/11/2011GL046812
}

Using globally distributed stations, we invert ratios of bodywave spectra for the $\mathrm{P}$-wave and $\mathrm{S}$-wave attenuation parameters $t_{P}^{*}$ and $t_{S}^{*}$. We compare our maps of $t_{P}^{*}$ and $t_{S}^{*}$ to surface-wave $Q$ tomography and attenuation maps inferred from a thermal interpretation of shear-velocity tomography.

\section{Spectral Analysis of $\mathbf{P}$ and $\mathbf{S}$ Waves}

[4] The attenuation parameter $t^{*}$ is defined as the ratio between the body-wave traveltime $t$ and the quality factor $Q$ along the (ray) path L [e.g., Stein and Wysession, 2003]:

$$
t^{*}=\int_{L} \frac{\mathrm{d} t}{Q} .
$$

If we write the spectrum $O(\omega)$ as the product of the source spectrum $S(\omega)$ and the attenuation function $e^{-\omega t^{* / 2}}$,

$$
O(\omega)=S(\omega) e^{-\omega t^{*} / 2}
$$

the logarithm of the spectral ratio $R_{i j}$ between $O_{i}(\omega)$ and $O_{j}(\omega)$,

$$
\ln R_{i j}(\omega)=-\frac{\omega}{2} \Delta t_{i j}^{*}
$$

is linearly related to the difference between the attenuation parameters at stations $i$ and $j$. Here, $\Delta t_{i j}^{*}=t_{i}^{*}-t_{j}^{*}$.

[5] To isolate the influence of intrinsic attenuation on $t^{*}$ from other sources such as crustal amplification, scattering, focusing and defocusing, we use large number of spectral ratio measurements. Our data set comprises 190,000 P- and $\mathrm{S}$-wave spectral ratios from broadband recordings of 250 earthquakes with magnitudes larger than 6 . The earthquake focal depths are larger than $200 \mathrm{~km}$ to ensure short sourcetime functions and to avoid interference of the direct $\mathrm{P}-$ and $\mathrm{S}$-waves with the surface reflections $\mathrm{pP}, \mathrm{sP}$, and $\mathrm{sS}$. We analyze the spectra at teleseismic distances $\left(30^{\circ}-85^{\circ}\right)$ to avoid waveform complexities from triplication in the transition zone and diffraction along the core-mantle boundary. We select 10-30 s long segments of $\mathrm{P}$-wave and $\mathrm{S}$-wave signals with impulsive onsets, low-amplitude coda, high signal-tonoise ratios, and similar waveforms for the same earthquakes. To minimize the variations of spectra due to varying source azimuths, we measure $\Delta t_{P}^{*}$ for station pairs that have similar azimuths.

[6] We determine $\ln R(\omega)$ up to a frequency of $0.8 \mathrm{~Hz}$ using the multiple-taper spectral analysis method of Lees and Park [1995]. $\Delta t_{P}^{*}$ (for P-waves) and $\Delta t_{S}^{*}$ (for S-waves) and $2 \sigma$ uncertainties are estimated by linear regression of $\ln R(\omega)$. We apply a correction using the results of Hwang and Ritsema [2011] to account for the systematic increase 

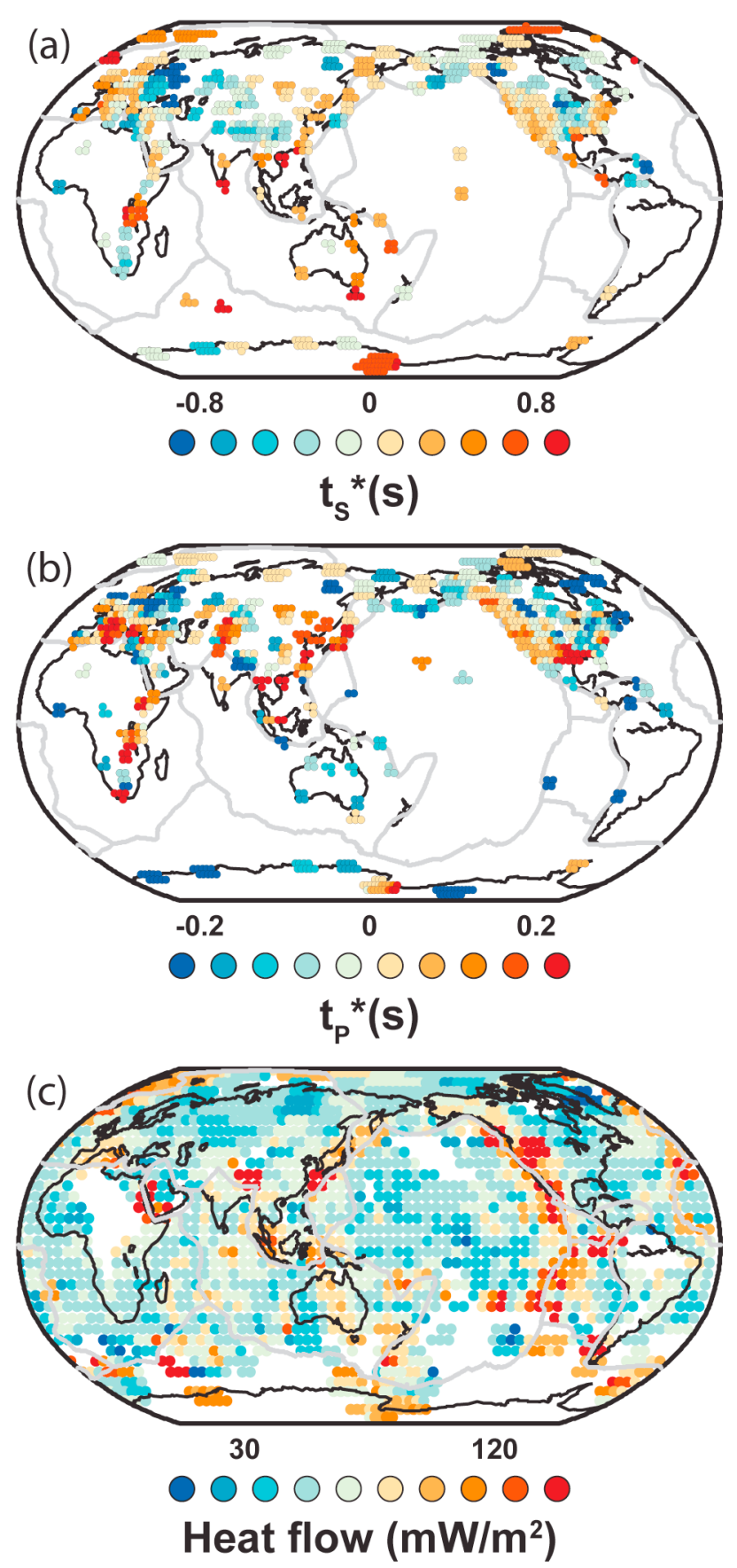

Figure 1. Spatial variations of (a) $t_{S}^{*}$ and (b) $t_{P}^{*}$ in the upper mantle. The $t_{S}^{*}$ and $t_{P}^{*}$ values have been averaged using overlapping caps with radii of $3^{\circ}$. Note that variations in $t_{S}^{*}$ and $t_{P}^{*}$ are similar. (c) Global heat flow distribution according to Pollack et al. [1993].

of $t_{P}^{*}$ and $t_{S}^{*}$ in the teleseismic distance range by about $0.2 \mathrm{~s}$ and $0.7 \mathrm{~s}$, respectively.

[7] Station-specific $t_{P}^{*}$ and $t_{S}^{*}$ values are determined by least-squares inversion of the $\Delta t_{P}^{*}$ and $\Delta t_{S}^{*}$ measurements. Since we cannot infer absolute values from spectral ratios, we constrain the mean values of $t_{P}^{*}$ and $t_{S}^{*}$ to be zero. We regularize the inversion by reducing the weight of $\Delta t_{P}^{*}$ and $\Delta t_{S}^{*}$ measurements with large $2 \sigma$ uncertainties and measurements for large inter-station distances. Details of the
$\Delta t^{*}$ measurements and uncertainties are given by Hwang et al. [2009] and Hwang and Ritsema [2011].

\section{Results}

\subsection{Lateral $t_{P}^{*}$ and $t_{S}^{*}$ Variations}

[8] Since $t_{P}^{*}$ and $t_{S}^{*}$ are affected by wave scattering and near-surface 'site-responses', we investigate the average values of $t_{P}^{*}$ and $t_{S}^{*}$ within overlapping circles with radii of $3^{\circ}$ (Figures $1 \mathrm{a}$ and $1 \mathrm{~b}$ ). The averaging of the data brings out the large-scale patterns of $t_{P}^{*}$ and $t_{S}^{*}$ that reflect global tectonics and that are similar to the global heat flow variations (Figure 1c).

[9] The spatial variations of $t_{P}^{*}$ and $t_{S}^{*}$ are similar and the ratio of $t_{P}^{*}$ and $t_{S}^{*}$ variances $(\sim 4)$ is consistent with the expected ratio of 4.5 for the upper mantle $Q$ structure of PREM [Dziewonski and Anderson, 1981] and the conventional value of 3.5 for the $t_{S}^{*} / t_{P}^{*}$ ratio [e.g., Cormier, 1982] (Figure 2). This indicates that variations in $t_{P}^{*}$ and $t_{S}^{*}$ do indeed reflect the lateral variation of intrinsic attenuation in the upper mantle.

\subsection{Joint Inversion for $t_{S}^{*}$}

[10] In Figure 3a, we show the map of $t_{S}^{*}$ by a joint inversion of $\Delta t_{P}^{*}$ and $\Delta t_{S}^{*}$. To relate the $\Delta t_{P}^{*}$ data to $\Delta t_{S}^{*}$ in the upper mantle, we have used

$$
\Delta t_{S}^{*}=\frac{3}{4} \frac{\int\left(V_{P}^{2} / V_{S}^{3}\right) \mathrm{d} s}{\int\left(1 / V_{P}\right) \mathrm{d} s} \Delta t_{P}^{*}
$$

using velocity structures $\left(V_{P}\right.$ and $\left.V_{S}\right)$ of PREM and assuming that $\Delta t^{*}$ is due to laterally varying $Q$ in the upper mantle only and that bulk attenuation is negligible [e.g., Anderson and Given, 1982].

[11] Figure 3a shows the global distribution of $t_{S}^{*}$ in a map that has been smoothed by cap-averaging. High attenuation characterizes tectonically active collision zones, rift zones and back-arc regions, while low attenuation is found below stable continental cores. For example, $t_{S}^{*}$ is relatively high in the tectonically-active western North America and low in

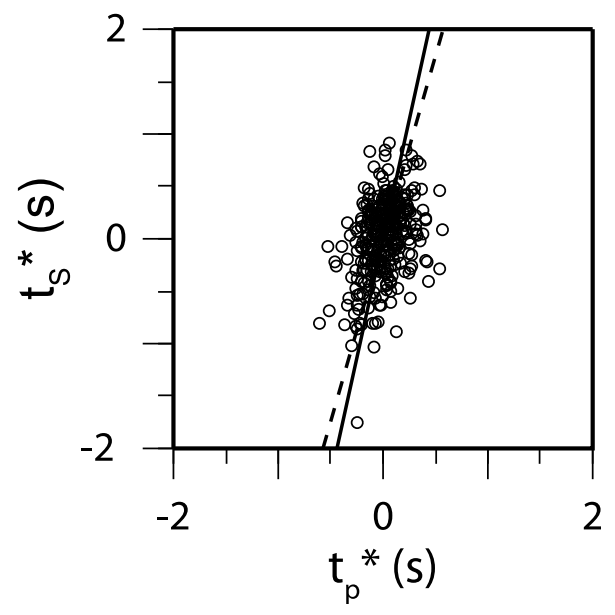

Figure 2. The correlation of $t_{S}^{*}$ versus $t_{P}^{*}$ after correction for epicentral distance. The solid line represents $t_{S}^{*}=4.5 t_{P}^{*}$ as predicted by the PREM velocity and $Q$ structures and the dashed line represents $t_{S}^{*}=3.5 t_{P}^{*}$, the ratio for conventional $t_{S}^{*}$ to $t_{P}^{*}$ ratio values reviewed by Cormier [1982]. 


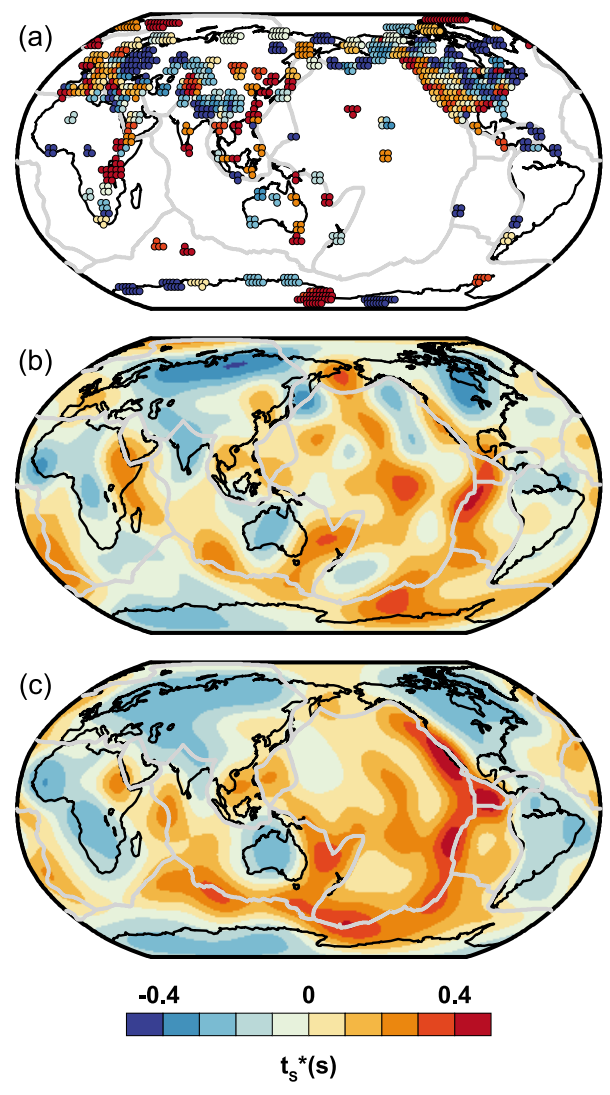

Figure 3. Spatial variation of $t_{S}^{*}$ in the upper mantle estimated (a) by joint inversion of $\Delta t_{P}^{*}$ and $\Delta t_{S}^{*}$, (b) from the surface-wave $Q$ model of Dalton et al. [2008] ( $\left.t_{Q}^{*}\right)$, and (c) from the thermal interpretation of S20RTS $\left(t_{T}^{*}\right)$. The correlation coefficient between $t_{S}^{*}$ (Figure $3 \mathrm{a}$ ) and $t_{Q}^{*}$ (Figure $3 \mathrm{~b}$ ) and between $t_{S}^{*}$ (Figure 3a) and $t_{T}^{*}$ (Figure 3c) are about 0.3 .

the platforms of central and eastern North America. A similar contrast is also apparent in Europe: $t_{S}^{*}$ is higher in western Europe than in the Baltic shield region. Station density is lower in other regions but a pattern consistent with tectonics persists. For example, $t_{S}^{*}$ is low in the East African Rift region and high at stations within the western and southern cratons of Africa. In addition, $t_{S}^{*}$ is high in the back-arc regions of the western Pacific subduction zones.

\subsection{Comparison With Seismic Tomography}

[12] We compare the map of $t_{S}^{*}$ based on the spectral ratios of $\mathrm{P}$ - and S-waves with the $t_{S}^{*}$ variation computed by integrating through two $Q$ models for the upper $400 \mathrm{~km}$ of the mantle using (1). In Figure 3b, we show the distribution of $t_{S}^{*}$, and denote it as $t_{Q}^{*}$, predicted by the model QRFSI12 [Dalton et al., 2008] for the upper mantle. QRFSI12 is a spherical harmonic degree-12 model of shear attenuation derived using fundamental-mode Rayleigh-wave amplitudes in the long-period range (50-250 s). The data set of Rayleighwave amplitudes are corrected for source, instrument, and focusing effects.

[13] In Figure 3c, we show $t_{S}^{*}$, and denote it as $t_{T}^{*}$, for the $Q$ structure based on a thermal interpretation of S20RTS [Ritsema et al., 1999] shear-velocity anomalies with respect to the Ocean Reference Model of Ritsema and Allen [2003]. For the conversion from $d V_{S}$ to temperature anomalies we assume that the mantle has a homogeneous pyrolitic composition and that below a PREM lithospheric structure, the average velocity profile corresponds to a mantle adiabat with a potential temperature of $1300^{\circ} \mathrm{C}$. Elastic velocities are calculated using a finite-strain approach [Cammarano et al., 2003; Goes et al., 2005] with a correction for anelastic effects using an Arrhenius-type pressure and temperature-dependent $Q$ formulation [Karato, 1993; Goes et al., 2005]: $Q_{S}(T, P)=$ $Q_{0} \exp \left\{g T_{m}(P) / T\right\}$, where $T$ and $P$ are absolute temperature and pressure, respectively, $Q_{0}=0.1 \omega^{0.15}, g(=40)$ is a scaling factor, and $T_{m}$ is the peridotite solidus. The conversion yields temperature, and corresponding $V_{P}$, density, $Q_{S}$ and $Q_{P}$. Regional models under North America, Europe and Australia converted in a similar manner yielded temperatures that could reconcile observed $V_{P}, V_{S}$ and surface heat flow [Goes et al., 2000, 2005; Goes and van der Lee, 2002]. The long-wavelength thermal structure inferred from S20RTS has reasonable temperatures varying between $600^{\circ} \mathrm{C}$ and $1450^{\circ} \mathrm{C}$ at $100 \mathrm{~km}$ depth and $1200-1550^{\circ} \mathrm{C}$ at $300 \mathrm{~km}$ depth (Figure 4).

\section{Discussion}

[14] There is a remarkable similarity between $t_{S}^{*}, t_{O}^{*}$, and $t_{T}^{*}$. This indicates that surface-wave amplitudes and bodywave spectra are affected by the same long-wavelength
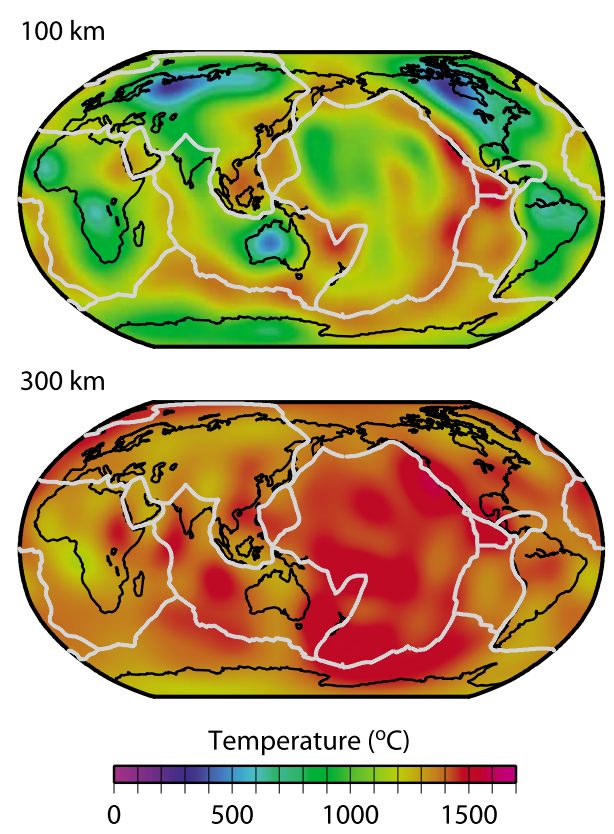

Figure 4. Temperatures at depths of (top) $100 \mathrm{~km}$ and (bottom) $300 \mathrm{~km}$ inferred from S20RTS [Ritsema et al., 1999] using the conversion of Goes et al. [2005]. The temperatures at $100 \mathrm{~km}$ reflect surface tectonics. The temperature is relatively low beneath old, stable cratons and relatively high below mid-ocean ridges. The high temperatures behind circum-Pacific subduction zones are likely biased high by high water content in the mantle wedge. At $300 \mathrm{~km}$ depth, a weak thermal imprint persists below the base of the cratonic roots, while relatively hot regions have largely lost their correlation with ridge geometry. Narrow subducting slabs are not resolved in this long-wavelength model. 
variation in attenuation even though the wavelengths and propagation directions of surface-waves and body-waves are entirely different.

[15] The variations in $t_{S}^{*}$ values are larger than the variations in $t_{Q}^{*}$ and $t_{T}^{*}$. For example, the contrast between western North America and stable North America and between western Europe and the Baltic region is about $0.7 \mathrm{~s}$ in $t_{S}^{*}$ but about $0.3 \mathrm{~s}$ and $0.5 \mathrm{~s}$ for $t_{Q}^{*}$ and $t_{T}^{*}$, respectively. However, these differences are to be expected given the uncertainties originating from averaging $\left(t_{S}^{*}\right)$, the regularization of the inverse problem $\left(t_{Q}^{*}\right)$, and uncertainties of the velocity-temperature conversion $\left(t_{T}^{*}\right)$.

[16] The correlation between patterns in $t_{S}^{*}$, surface heat flow, tectonics and shear-velocity anomalies suggest attenuation is largely the result of thermally activated creep. The conclusion that temperature exerts the main control on global $Q_{S}$ and $V_{S}$ structures is consistent with other studies [Artemieva et al., 2004; Dalton et al., 2009; Dalton and Faul, 2010]. Our analyses illustrate that the maps of $t_{S}^{*}$ and $t_{Q}^{*}$ can be explained by variations of intrinsic attenuation consistent with a temperature variation as that depicted in Figure 4.

[17] Other factors such as the presence of melt below midocean ridges and a melt-depleted composition of cratonic roots likely have additional influence [Artemieva et al., 2004; Dalton et al., 2009; Dalton and Faul, 2010]. The back-arc high $t_{S}^{*}$ and $t_{O}^{*}$ anomalies that coincide with low shear velocities, which we have interpreted as high temperatures, may partially reflect high water content compatible with an interpretation of regional $V_{P}, V_{S}$, and $Q_{P}$ below the Izu-Bonin arc [Shito et al., 2006]. To better distinguish between different mechanisms requires an imaging of $t_{S}^{*}, t_{P}^{*}$, and seismic velocities at more similar resolution and scale than the models we compared here.

\section{Conclusions}

[18] New maps of $t_{P}^{*}$ and $t_{S}^{*}$, derived from 190,000 teleseismic, global $\mathrm{P}$-wave and $\mathrm{S}$-wave spectra, exhibit a coherent large-scale spatial variation that is consistent with heat flow and tectonic variations. The ratio of $t_{S}^{*}$ to $t_{P}^{*}$ is consistent with the PREM ratio of 4.5 and the conventional $t_{S}^{*}$ to $t_{P}^{*}$ ratio of 3.5. Moreover, a joint inversion of the $\mathrm{P}$-wave and $\mathrm{S}$-wave spectral ratios yields lateral variation of $t_{S}^{*}$ that is similar to the predicted $t_{S}^{*}$ variation for a recent surface-wave $Q$ model $\left(t_{Q}^{*}\right)$ of the upper mantle and a thermal interpretation of shear-velocity anomalies in the upper mantle $\left(t_{T}^{*}\right)$. Combined these observations indicate that the largescale pattern in $t_{P}^{*}$ and $t_{S}^{*}$ reflects variations in intrinsic shear attenuation.

[19] The high correlation between $t_{S}^{*}$ and $t_{Q}^{*}$ indicates that coherent patterns of attenuation can be constrained from large data sets of horizontally and vertically propagating waves. The similarity between $t_{S}^{*}, t_{Q}^{*}$, and $t_{T}^{*}$ suggests that the patterns of Figure 3 predominantly reflects variable attenuation in the upper few hundred kilometers of the mantle. The patterns are consistent with a thermal structure of the mantle as inferred from shear velocity anomalies.

[20] Acknowledgments. We thank the two anonymous reviewers for their constructive comments. This research was funded by NSF grant EAR-0944167. Data were provided by the IRIS/DMC.
[21] The Editor thanks the two anonymous reviewers for their assistance in evaluating this paper.

\section{References}

Anderson, D. L. (1967), The anelasticity of the mantle, Geophys. J. R. Astron. Soc., 14, 135-164.

Anderson, D. L., and J. W. Given (1982), Absorption band Q model for the Earth, J. Geophys. Res., 87, 3,893-3,904.

Artemieva, I. M., M. Billien, J.-J. Lévêque, and W. D. Mooney (2004), Shear wave velocity, seismic attenuation, and thermal structure of the continental upper mantle, Geophys. J. Int., 157, 607-628.

Bhattacharyya, J., G. Masters, and P. Shearer (1996), Global lateral variations of shear wave attenuation in the upper mantle, J. Geophys. Res., $101,22,273-22,289$.

Billien, M., J.-J. Lévêque, and J. Trampert (2000), Global maps of Rayleigh wave attenuation for periods between 40 and 150 seconds, Geophys. Res. Lett., 27, 3,619-3,622.

Cammarano, F., S. Goes, P. Vacher, and D. Giardini (2003), Inferring upper-mantle temperatures from seismic velocities, Phys. Earth Planet. Inter., 138, 197-222.

Cormier, V. F. (1982), The effect of attenuation on seismic body waves, Bull. Seismol. Soc. Am., 72, S143-S173.

Dalton, C. A., and G. Ekström (2006), Global models of surface wave attenuation, J. Geophys. Res., 111, B05317, doi:10.1029/2005JB003997.

Dalton, C. A., and U. H. Faul (2010), The oceanic and cratonic upper mantle: Clues from joint interpretation of global velocity and attenuation models, Lithos, 120, 160-172.

Dalton, C. A., G. Ekström, and A. M. Dziewonski (2008), The global attenuation structure of the upper mantle, J. Geophys. Res., 113, B09303, doi:10.1029/2007JB005429.

Dalton, C. A., G. Ekström, and A. M. Dziewonski (2009), Global seismological shear velocity and attenuation: A comparison with experimental observations, Earth Planet. Sci. Lett., 284, 65-75.

Dziewonski, A. M., and D. L. Anderson (1981), Preliminary reference Earth model, Phys. Earth Planet. Inter., 25, 297-356.

Faul, U. H., J. D. Fitz Gerald, and I. Jackson (2004), Shear wave attenuation and dispersion in melt-bearing olivine polycrystals: 2 . Microstructural interpretation and seismological implications, J. Geophys. Res., 109, B06202, doi:10.1029/2003JB002407.

Goes, S., and S. van der Lee (2002), Thermal structure of the North American uppermost mantle inferred from seismic tomography, J. Geophys. Res., 107(B3), 2050, doi:10.1029/2000JB000049.

Goes, S., R. Govers, and P. Vacher (2000), Shallow mantle temperatures under Europe from P and S wave tomography, J. Geophys. Res., 105, $11,153-11,169$

Goes, S., F. J. Simons, and K. Yoshizawa (2005), Seismic constraints on temperature of the Australian uppermost mantle, Earth Planet. Sci. Lett., 236, 227-237.

Gung, Y., and B. Romanowicz (2004), $Q$ tomography of the upper mantle using three-component long-period waveforms, Geophys. J. Int., 157, 813-830.

Hammond, W. C., and E. D. Humphreys (2000), Upper mantle seismic wave velocity: Effects of realistic partial melt geometries, J. Geophys. Res., 105, 10,975-10,986.

Hwang, Y. K., and J. Ritsema (2011), Radial $Q_{\mu}$ structure of the lower mantle from teleseismic body-wave spectra, Earth Planet. Sci. Lett., 303, 369-375.

Hwang, Y. K., J. Ritsema, and S. Goes (2009), Spatial variations of P wave attenuation in the mantle beneath North America, J. Geophys. Res., 114 B06312, doi:10.1029/2008JB006091

Jackson, I., J. D. Fitz Gerald, U. H. Faul, and B. H. Tan (2002), Grain-sizesensitive seismic wave attenuation in polycrystalline olivine, J. Geophys. Res., 107(B12), 2360, doi:10.1029/2001JB001225.

Karato, S.-I. (1993), Importance of anelasticity in the interpretation of seismic tomography, Geophys. Res. Lett., 20, 1623-1626.

Karato, S.-I., and H. Jung (1998), Water, partial melting and the origin of the seismic low velocity and high attenuation zone in the upper mantle, Earth Planet. Sci Lett., 157, 193-207.

Lawrence, J. F., and M. E. Wysession (2006), Seismic evidence for subduction-transported water in the lower mantle, in Earth's Deep Water Cycle, Geophys. Monogr. Ser., vol. 168, edited by S. D. Jacobsen and S. van der Lee, pp. 251-261, AGU, Washington, D. C.

Lees, J. M., and J. Park (1995), Multiple-taper spectral analysis: A standalone C-subroutine, Comput. Geosci., 21, 199-236.

Pollack, H. P., S. J. Hurter, and J. R. Johnson (1993), Heat flow from the Earth's interior: Analysis of the global data set, Rev. Geophys., 31, 267-280.

Reid, F. J. L., J. H. Woodhouse, and H. J. van Heijst (2001), Upper mantle attenuation and velocity structure from measurements of differential $\mathrm{S}$ phases, Geophys. J. Int., 145, 615-630. 
Ritsema, J., and R. M. Allen (2003), The elusive mantle plume, Earth Planet. Sci. Lett., 207, 1-12.

Ritsema, J., H. J. van Heijst, and J. H. Woodhouse (1999), Complex shear velocity structure imaged beneath Africa and Iceland, Science, 286, 1925-1928.

Romanowicz, B. (1995), A global tomographic model of shear attenuation in the upper mantle, J. Geophys. Res., 100, 12,375-12,394.

Romanowicz, B. (2008), Using seismic waves to image Earth's internal structure, Nature, 447, 198-201.

Selby, N. D., and J. H. Woodhouse (2002), The Q structure of the upper mantle: Constraints from Rayleigh wave amplitudes, J. Geophys. Res., 107(B5), 2097, doi:10.1029/2001JB000257.

Shito, A., S.-I. Karato, K. N. Matsukage, and Y. Nishihara (2006), Towards mapping the three-dimensional distribution of water in the upper mantle from velocity and attenuation tomography, in Earth's Deep Water Cycle, vol. 168, edited by S. D. Jacobsen and S. van der Lee, pp. 225-236, AGU, Washington, D. C.

Stein, S., and M. E. Wysession (2003), An Introduction to Seismology, Earthquakes, and Earth Structure, 498 pp., Blackwell, Malden, Mass.

Warren, L. M., and P. M. Shearer (2002), Mapping lateral variations in upper mantle attenuation by stacking $P$ and $P P$ spectra, $J$. Geophys. Res., 107(B12), 2342, doi:10.1029/2001JB001195.

S. Goes, Department of Earth Science and Engineering, Imperial College London, London SW7 2AZ, UK. (s.goes@imperial.ac.uk)

Y. K. Hwang and J. Ritsema, Department of Geological Sciences, University of Michigan, Ann Arbor, MI 48109, USA. (ykhwang@umich. edu; jritsema@umich.edu) 